\title{
El Verdadero Don Segundo en Don Segundo Sombra de Ricardo Güiraldes
}

To pocos lectores de Don Segundo Sombra se deben de haber preL guntado si don Segundo, el pintoresco protagonista de la novela de Ricardo Güiraldes, es un personaje real o ficticio. ${ }^{1}$ El mismo autor nos ha dado la respuesta. Sus palabras fueron recogidas por el escritor francés Francis de Miomandre, que se encontró con Güiraldes en París, en I920.2

En el curso de aquel año Güiraldes asistía a las tertulias de literatos franceses que se daban cita en la Maison des Livres, la pequeña pero famosa librería de Adrienne Monnier, en la rue de l'Odéon, donde aquél fue presentado por Valéry Larbaud. Después de Navidad Güiraldes volvió a su tierra argentina para empezar a trabajar en Don Segundo Sombra. ${ }^{3}$ En una de las reuniones de la Maison des Livres, poco antes de su retorno, dijo a su amigo Miomandre: "Pienso regresar a la Argentina para escribir la historia de un hombre que me acompaña desde niño".4

Pues bien, el hombre a quien se refería Güiraldes era Segundo Ramírez, un viejo paisano que se presentó hacia el año rgoo en La Porteña, estancia de los Güiraldes, en la provincia de Buenos Aires, a unos pocos kilómetros de la pequeña población de San Antonio de Areco. ${ }^{5}$ Al parecer venía de muy lejos. Aquella figura que emergía de lo desconocido, con su indumentaria característica, de tan marcado relieve local, impre-

1 Véase T. B. Irving, "Myth and Reality in 'Don Segundo Sombra," Hispanic. XL (March, 1957) 44-48; también David T. Sisto, "A Possible Fictional Source for Don Segundo Sombra", Hispania, XLII (March, 1959), 75-78.

2 Francis de Miomandre, "Recuerdos de Güiraldes", La Nación (Buenos Aires, 7 de enero de 1940).

3 Ismael B. Cólombo, Ricardo Güiraldes; poeta de la pampa (San Antonio de Areco, 1952), p. 70.

4 Miomandre, Loc. cit.

5 Herbert B. Smith, "El amor y la mujer a través de Don Segundo Sombra", Cuadernos Rioplatenses (La Plata, 1959), p. 11; Colombo, p. 95. 
sionó a Ricardo, todavía muchacho, como la personificación de las gestas pampeanas. Ricardo tenía entonces trece años. ${ }^{6}$

Por lo que se cree, don Segundo nació en Coronda, ${ }^{7}$ provincia de Santa $\mathrm{Fe}$, el 2 de julio de $1852,{ }^{8}$ de modo que se acercaba a los cincuenta años de edad en el momento de su llegada a la estancia. Fueron su padres Patricio y Carmen, esclavos manumisos que estuvieron al servicio de don Santiago Ramírez, cuyo apellido adoptó don Segundo. ${ }^{9}$. Su madre era india auténtica. ${ }^{10}$ De muchacho, llevó don Segundo una vida bastante dura, sobre todo mientras trabajaba en las estancias de los Núñez. ${ }^{11}$ Desde que se hizo resero, viajó continuamente, y decíase que más de una vez estuvo enredado en serias dificultades con la policía, ${ }^{12}$ pero no se conoce ningún incidente que corrobore esta creencia. Lo probable es que su vida vagabunda, envuelta en el misterio, sumada a su aspecto más bien temible, hiciera sospechar en él algo del "gaucho malo" de la tradición. Llegó a La Porteña cansado de tantos años de andanzas y fatigas, y quedó allí como encargado del "puesto" La Lechuza. ${ }^{13}$

Su apariencia física era impresionante. Tenia la piel morena y curtida como cuero y los ojos achicados por el hábito de escudriñar el horizonte. ${ }^{1 / 4}$ Su frente estrecha, sus pómulos prominentes y su quijada enérgica recordaban su origen parcialmente indio. ${ }^{15}$ Grande de cuerpo, pero con las piernas cortas en relación a su largo torso, parecia más grande

\footnotetext{
6 Adelina del Carril de Güiraldes, "Nota preliminar", Don Segundo Sombra (Buenos Aires, Ed. Kraft, 1952), p. 11.

7 Germán Berdiales, "El gaucho en las letras. Don Segundo Sombra y su creador: Ricardo Güiraldes", Pampa Argentina (Buenos Aires, XXI, octubre de 1947), 20.

8 Eduardo Jorge Bosco, "Un viaje a San Antonio de Areco", Buenos Aires Literaria (Año I, n. 2, noviembre de 1952), p. 22.

- Aristóbulo Echegaray, Don Segundo Sombra, reminiscencia infanitl de $R ;$ cardo Güiraldes (Buenos Aires, 1955), p. 38.

10 Adelina del Carril de Güiraldes, en carta fechada el 6 de junio dirigida a Giovanni Previtali, dijo: "Su madre era india auténtica".

11 Julián Fernández Hutter, El alma errante de "Don Segundo Sombra" (Santa Fe, 1945).

12 Juan Carlos Neyra, El mito gaucho en "Don Segundo Sombra" (Bahía Blanca, 1952), p. 12 .

13 Germán Berdiales, p. 20. "Puesto" en la Argentina es una sección de la estancia a cargo de una persona, la que por lo común se instala allí con su familia.

I4i Silverio Boj (W. G. Weyland), Ubicación de "Don Segundo Sombra" $y$ otros ensayos (Tucumán, i940), p. 26.

15 Germán Berdiales, "Ramón Subiratz, el pintor que retrató a Don Segundo Sombra", Pampa Argentina (Buenos Aires, XXIII, junio de 1949), 20, 30.
} 
aún cuando montaba a caballo. ${ }^{16}$ Usaba chiripá, lo que ponía de resalto su semejanza con el gaucho legendario. ${ }^{17}$

Además de la incógnita de su pasado, realzaba el prestigio de don Segundo la estimación general que se guardaba por aquella raza viril de "reseros".18 Se ha dicho que el joven Güiraldes, al contemplar al viejo. paisano como al último de los gauchos, admiraba en él su hombría, su indiferencia ante el peligto, su destreza en el manejo del ganado y su es... píritu afirmativo. ${ }^{19} \mathrm{La}$ disposición taciturna de don Segundo aguzaba ell deseo del muchacho de extraer de él reminiscencias y cuentos. A veces. don Segundo solía hablar del pasado, y en ocasiones, llevado por su malicia criolla, relataba alguna bribonería gauchesca, de su invención. $Y$ a: pesar de su inclinación a lo lacónico, se destacaba como narrador de cuentos, entre ellos los de magia negra y magia blanca y de animales que hablaban como hombres. ${ }^{20}$

En su aspecto más frívolo, conocia los bailes regionales y sabía improvisar coplas al estilo de los payadores. ${ }^{21}$ Tenia también su vena zumbona, con un modo muy suyo de ver el lado cómico de sus semejantes, a los que ponía en solfa con sus breves comentarios irónicos. ${ }^{22}$

Pero, contrariamente a la impresión general, don Segundo no gozaba de una reputación enteramente favorable. Sus agudezas mordaces, expresadas con su voz de falsete, no siempre hacian mucha gracia a sus camaradas de la estancia. ${ }^{23}$ Decíase que en su vida pasada se las echaba de guapo, inclinado a la riña, y que en más de una ocasión "marcó" a su adversario con algún tajo de mala ley. ${ }^{24}$

Así, pues, mientras Ricardo veía en don Segundo personificación del gaucho noble, otros no compartían este punto de vista afectuoso. Pero ciertas características trascendían de las opiniones favorables o desfavora-

16 Se han publicado reproducciones de las fotografías de Segundo Ramírez en la edición Pleamar de Don Segundo Sombra (Buenos Aires, 1943), p. 32; en el artículo "Ricardo Güiraldes, vecino de Areco", por Ismael Colombo, Farol (Buenos Aires, septiembre de 1953), p. 4; y en el trabajo "Cómo apareció Don Segundo Sombra", por Augusto Mario Delfino, Arte y Plata (México, III, febrero de 1947), pp. 34-36.

17 Berdiales, pp. 20-30.

18 Neyra, p. 12 "Resero" es el conductor de ganado vacuno y en general el peón de estancia.

19 Arturo Torres-Rioseco, "Definición de Don Segundo Sombra", La novela iberoamericana (Albuquerque, New México), p. 127.

20 Boj, p. 27.

21 Kenneth Porter Kirwood, "Ricardo Güiraldes and Don Segundo Sombra", Excursion Among Books (Buenos Aires, 1949), pp. 315-329.

22 Bosco, p. 19.

23 Ibíd.

24 Neyra, p. 12. 
bles que inspiraba: don Segundo eta silencioso, varonil, macizo. Como vaquero poseía una pericia que todos apreciaban. Se le respetaba como individuo, sea por admiración o por temor; la austeridad de su carácter, sin embargo, estaba atemperada, como hemos visto, por algunos rasgos ocasionales de buen humor.

La amistad entre el viejo y el muchacho estaba destinada a durar para siempre, y llevó a Güitaldes, en los últimos años de su vida, a escribir su obra maestra, Don Segundo Sombra. Güiraldes murió en París en octubre de $1927 .^{25}$ En noviembre sus restos fueron llevados a San Antonio de Areco.26 Allá, junto con Leopoldo Lugones y Ricardo Rojas, don Segundo bajó al joven patrón a la fosa. ${ }^{27}$

En I936 don Segundo vivía con una hija casada en San Antonio de Areco. Tenía ochenta y cuatro años, estaba cojo por el reumatismo y completamente sordo, pero retenía algunas de sus características de antaño. Vestía su viejo chiripá, soltaba alguna que otra agudeza en unos pocos comentarios típicamente personales y no olvidaba su antigua afección por "don Ricardo". 28 Murió el 20 de agosto de ese año. Escoltado por cuatro gauchos, fue enterrado en el mismo pedazo de pampa donde descansa $\mathrm{Ri}$ cardo Güiraldes. ${ }^{29}$

Giovanini Previtali

Pablo MAX YNSFRAIN

Universidad de Puerto Rico, en Mayagüez.

University of Texas

25 Ortiz Echagüe, "La atribulante noticia", El Mentor (San Antonio de Areco, 14 de octubre de 1928), p. 1.

26 José R. Liberal, "Prólogo", Don Segundo Sombra de Ricardo Güiraldes (Buenos Aires), p. 18.

27 Francisco Luis Bernández, "Ricardo Güiraldes en mi recuerdo", Crite. rio (Buenos Aires, XXVI, 1952), p. 875.

28 Loc. cit.

Q9 Ibíd. 